Marina Mijatović ${ }^{1}$,

Nezavisni univerzitet Banja Luka, Pedagoški Fakultet, Banja Luka, Republika Srpska - Bosna i Hercegovina
UDC: $371.213: 159.928 .23$

doi: $10.19090 /$ ps.2019.2.168-176

Primljen: 28. 8. 2019.

Prihvaćen: 6. 11. 2019.

STRUČNI NAUČNI RAD

\title{
ULOGA I ZNAČAJ NASTAVNIKA U VASPITNO- -OBRAZOVNOM RADU SA DAROVITIMA
}

\author{
Apstrakt
}

U naučnoj i stručnoj javnosti prihvaćen je stav da obrazovanje u doba postmoderne treba da omogući svakom pojedincu da ostvari svoje predispozicije i razvije sposobnosti do individualnog optimuma, čime se u fokus sve više stavlja pitanje darovitih učenika. Darovitost je lična ali i društvena potreba jer daroviti učenici mogu, uz adekvatan pedagoški tretman, da izrastu u društvenu elitu. Stoga, briga za darovitu decu jedan je od bitnih zadataka stučnih saradnika, nastavnika i vaspitača. Nastavnici danas imaju zahtevne $i$ složene profesionalne uloge a od velikog je značaja njihova mogućnost korišćenje različitih metoda i didaktičko-metodičkih postupaka kako bi se zadovoljile specifične potrebe darovitih. Ovaj teorisjki rad ima za cilj da ukaže na kompleksnu ulogu nastavnika u radu sa darovitima, od procesa nominacije pa do organizacije vaspitno-obrazovnog rada, kao i da pruži određene smernice za organizovanje vaspitno-obrazovnog rada sa darovitim učenicima sa posebnim akcentom na mentorski rad.

Ključne reči: darovitost, nastavnik, vaspitno-obazovni rad.

\section{Uvod}

Pojam darovitosti nije novijeg datuma jer su o ovom pojmu govorili i veliki mislioci pedagoške istorije (Adžić, 2011). Darovitost i danas predstavlja važno pedagoško pitanje jer su daroviti pojedinci najvažniji resurs jednog društva i stub njegovog progresa a opšte je poznata činjenica da su sposobnim pojedincima potrebna izazovna i bogata iskustva kako bi ostvarili svoje potencijale (George, 2004). U savremenom diskursu o izazovima sa kojim se susreću daroviti, istraživači su tragali za brojnim pitanjima a jedno od njih je i pitanje uloge koju nastavnik zauzima u radu sa darovitim učenicima. Zahtevne i složene profesionalne uloge nastavnika uslovljene su

\footnotetext{
${ }^{1}$ mmijat13@gmail.com
} 
promenama vezanim za redefinisanje ciljeva i ishoda učenja, inoviranjem kurikuluma (Budimir-Ninković i Janković, 2016), većom autonomijom i participacijom učenika, ali i zahtevima za sistemskim i sistematskim podsticanjem darovitih (Babić-Kekez, 2010). Složenost ove tematike donosi puno pitanja o kojima promišljaju naši prosvetni radnici a jedno od njih se odnosi na organizaciju rada sa takvom decom. Zbog toga je važno šta nastavnik čini po pitanju prepoznavanja i uključivanja darovite dece u vaspitno-obrazovni proces, tj. pitanje uloge koju će zauzeti. Rad je podstaknut činjenicom da se svi nastavnici u svom radu susreću sa potencijalno darovitim detetom a njegov doprinos je u rasvetljavanju samo malog dela problema i potreba rada sa darovitima.

\section{Daroviti učenici i njihove specifičnosti}

Promišljanja na temu darovitosti imala su svoj razvojni put od stavljanja akcenta na biološki aspekt i biološku datost, pa sve do sagledavanja kompleksnosti ovog fenomena (Pavlović i Mijatović, 2016). Takođe, dugi niz godina, psiholozi su kao merilo darovitosti uzimali isključivo koeficijent inteligencije (IQ) (Altaras, 2006). Međutim, daroviti učenici razlikuju se od ostalih, ne isključivo po visini koeficijenta inteligencije već po mnogobrojnim svojstvima kao što su: kreativnost, imaginacija, oštroumnost ali i hrabrost, motivacija, empatija te socijalne veštine i moralni kapaciteti (Gojkov 2008; Rotigel, 2003; Stojanović 2016). Imajući u vidu navedena svojstva, jasno je da darovito dete ima specifične potrebe koje predstavljaju izazov za prosvetne radnike (Čudina-Obradović, 1990). Dakle, ovaj fenomen ne možemo koncipirati samo kao intelektualnu sposobnost jer je reč o specifičnom spoju crta ličnosti i izuzetnih sposobnosti pojedinca, te je opravdano govoriti o multidimezionalnom konstruktu.

Prilikom procesa identifikacije darovitih učenika, nastavnici bi trebalo da posebno obrate pažnju na: razvijene specifične sposobnosti (sportske, tehničke, dramske, likovne, muzičke i dr.), oštroumnost pri rešavanju problema, povezivanje uzroka i posledica ali i na organizovanje i povezivanje iskustava (Đorđević, 2005; Đorđević i Đorđević, 2015). Istinska motivisanost za područje u kojem su nadareni može biti još jedan indikator darovitosti, a taj interes može biti toliko jak da pojedini autori upozoravaju da se može graničiti sa opsesivnim (Winner, 2005) te da se darovitost može manifestovati i u ,čudnom obliku“ pa se neiskusnim nastavnicima može, takvo dete, činiti nemarnim, hiperaktivnim ili pak drskim (Grandić i Letić, 2009). Takođe, važno je spomenuti da darovitu decu prate pojedini stereotipi, mitovi i predrasude a jedan od njih (posebno opasan!) je i taj da darovitima nije potrebna pomoć jer će se snaći i sami, ako su zaista daroviti (Vaughn, Bos \& Schumm, 2009).

\section{Uloga nastavnika u radu sa darovitima}

U naučnoj i stručnoj javnosti prihvaćen je stav da obrazovanje u doba postmoderne treba da omogući svakom pojedincu da ostvari svoje predispozicije i razvije 
sposobnosti do individualnog optimuma. Takvi zahtevi nužno iziskuju promenu ponašanja učesnika u nastavnom procesu i menjaju tradicionalnu ulogu nastavnika ka „ulozi savetnika za učenje“ (Gojkov, 2016: 141), kao i kreativan odnos prema sopstvenom radu. Prvi zahtev koji se postavlja pred nastavnike, u radu sa darovitima, jeste uočavanje i prepoznavanje. Rana identifikacija darovitosti ključna je kako bi se mogla organizovati stimulativna sredina koja bi omogućila ispoljavanje njihove izuzetnosti te $u$ tom procesu nastavnik ne treba da dela sam. Nepohodna je saradnja sa roditeljima i stručnom službom, drugim učenicima, tj. sa onima koju su u kontaktu sa (potencijalno) darovitim učenicima, a identifikaciju darovitih treba posmatrati kao proces koji može da traje i par godina (Đorđević, 2005) jer je vrlo teško u određenom momentu, pouzdano, utvrditi darovitost kao konstantnu veličinu kod dece (Maksić, 1993). Autorka Đorđević naglašava da je dugotrajniji proces identifikacije darovitih, sa širokom lepezom informacija, pouzdan i dinamičan i da ,takva identifikacija omogućava i određeno vođenje darovitih do postignuća za koja su oni sposobni““(Đorđević, 2005: 42). U dokumentu Strategija implementacije i sprovođenja obrazovanja nadarenih $i$ talentovanih učenika izneti su višestruki kriterijumi koje je potrebno zadovoljiti u procesu identifikacije darovitih (Policy and implementation strategies for the education of gifted and talented students, 2004):

- postupci identifikacije moraju biti dinamički;

- mora postojati kontinuitet;

- neophodna je nepristrastnost i objektivnost;

- demokratičnost i humanost (svaki učenik treba da ima šansu za iskazivanje svojih potencijala)

Prilikom identifikacije darovitih, nastavnici mogu da slede sledeće etape tj. korake (koje mogu menjati svoj raspored): nominacija - proveravanje- nadgledanje (Koren, 1989). Nominaciju ne mora provesti isključivo nastavnik, ona može biti provedena $\mathrm{i}$ od strane roditelja, pedagoga, psihologa. Nakon procesa nominacije sledi proces proveravanja pomoću kojeg se mogu dobiti podaci objektivniji nego u prvom koraku. Treći korak, proces nadgledanja treba usmeriti ka prikupljanju informacija o interesovanjima, sposobnostima, jakim stranama učenika, slabim stranama učenika, o postignućima itd. (Strategija implementacije i sprovođenja obrazovanja nadarenih i talentovanih učenika, 2004). Celokupan proces identifikacije treba da rezultira smanjenjem broja učenika koji će biti uočeni kao daroviti, tako da korake identifikacije možemo posmatrati kao „filtere“. Koren (1989) naglašava da kako proces identifikacije teče, posmatra se sve manji broj učenika. Uviđamo, da se pred nastavnicima nalazi kompleksan proces identifikacije darovitih učenika koji zahteva pažljivo praćenje ponašanja reakcija i postignuća učenika, ali postavlja se pitanje šta je sa darovitima koji se teško prepoznaju ili pak podbacuju u uspešnosti? Pojedini autori naglašavaju da razlog tome može biti u prezastupljenosti standardizovanih testova ili u posmatranju darovitosti isključivo kao intelektualne kategorije (Coleman 2003; George 2004) te treba imati na umu da ne postoji univerzalna metoda identifikacije i da se u tom proce- 
su treba oslanjati na višestruke kriterijume. Pomoć nastavnicima u ovom slučaju mogu biti rezultati pojedinih istraživanja o karakteristikama darovitih koji ne postižu uspeh u školi. Neke od tih karakteristika su: neprihvaćenost od vršnjaka, manjak koncentracije, nezainteresovanost za socijalno prihvatanje i kritičnost prema drugima (George 2004). Još jedna od bitnih uloga nastavnika u radu sa darovitima jeste i podsticanje daljeg razvoja darovitih, što zahteva veliku indiviualizaciju u nastavi i orijentaciju na partnersku komunikaciju i socijalnu interakciju. Stojanović (2016) navodi da je osnova savremenih didaktičkih pristupa konstruktivistička metateorija koja posebni značaj pridaje dvosmernoj pedagoškoj komunikaciji i uspostavljanju partnerskih odnosa u učionici. Na ovaj način, stvaraju se uslovi za diskusiju i razmenu mišljenja jer se darovitost ne može ispoljiti u klimi nepoverenja ili u slučaju kada nastavnik ne prepozna i ne podstiče nove ideje učenika (Đorđević, 2005). Nastavnici u radu sa darovitim učenicima treba da koriste savremene nastavne metode i sredstva, mobilne tehnologije i aplikacije koje će omogućiti veću autonomiju ali i participaciju učenika. Na taj način u učionici će se smanjiti proces poučavanja a akcenat će biti na interaktivnom učenju. Prilikom ogranizacije vaspitno-obrazovnog rada sa darovitima, nastavnici treba da imaju u vidu i unutrašnje faktore darovitosti (motivacija, zadovoljstvo, odsustvo stresa i frustracija) a ne isključivo akademski uspeh.

\section{Organizacija rada sa darovitim učenicima}

Slabost našeg obrazovnog sistema ogleda se u tome što se učenici često izjednačavaju na prosečnom nivou (Djukić, Djermanov i Kosanović, 2012) te se na taj način ne uvažavaju individualne razlike među učenicima. Evidentno je da je sredinu za učenje neophodno transformisati u pravcu fleksibilnosti i individualnosti i u tu svrhu nastavnici treba da primenjuju raznovrsne metode i tehnike, problemsku i mentorsku nastavu, da omoguće učenicima rad na (istraživačkim) projektima ali i da iniciraju razne panel diskusije. Naime, upravo ovi modeli nastave odgovaraju stilu učenja darovitih učenika (Gallagher \& Gallagher, 2013). Grandić i Letić (2009) ističu da je u radu sa darovitima krucijalno podsticati samoinicijalno učenje a nastavnici to mogu ostvariti primenom različitih kreativnih tehnika kao što su: oluja ideja, mape uma, vođene fantazije, provokacije, humor itd. Problemi koji se postavljaju pred učenike, u problemski orijentisanoj nastavi, stimulišu darovite i zahtevaju određeni intelektualni napor kako bi se došlo do rešenja (Gallagher \& Gallagher, 2013) koji se u tim situacijama samostalniji u odnosu na svoje vršnjake (Swanson, 1992) i stavljaju se u situacije u kojima se suočavaju sa problemima, angažuju se za njihovo rešavanje i na koncu, formulišu sopstveni stav. Korak dalje, u radu sa darovitima, može biti metorski rad kao način komunikacije između nastavnika i učenika. Mentorski rad je uglavnom asocijacija na visokoškolsku nastavu ali to je jedan multidimenzinalan obrazovni proces koji se može primenjivati u osnovnim i srednjim školama (Babić-Kekez, 2010) a koji implicira multidimenzionalnu ulogu nastavnika jer je on $u$ isto vreme instruktor, savetnik, faci- 
litator ali i prijatelj. Na ovaj način, uvažavaju se postulati postmoderne filozofije koja naglašava kontekstualnu konstrukciju značenja i validnost višestrukih perspektiva jer je naša realnost multiperspektivna (Uhle 1993, prema: Gojkov, 2016). Mentorski rad treba da se zasniva na partnerskim odnosima čija se suština ogleda u poziciji učenika koji se od objekatske pomera ka subjekatskoj (Branković i Mikanović, 2011; Pavlović i Mijatović, 2016) što znači da darovit učenik ima veću autonomiju da donosi odluke zajedno sa nastavnikom. Rezultati istraživanja autorke Tomić (2012) potvrđuju da se mentorsko vođstvo nastavnika i stručno vođstvo nastavnika i profesora izdvajaju kao značajne varijable za razvoj ličnosti i ostvarivanje uspešnosti kod darovitih učenika.

Promene uloga i ponašanja učesnika u nastavnom procesu (pa i darovitih) treba da budu usmerene na slobodu izbora i preduzimanja različitih aktivnosti jer se na taj način pripremaju učenici za preuzimanje inicijativa pri rešavanju ličnih ali i društvenih pitanja (Gojkov, 2016). Uloga nastavnika u mentorskom radu izrazito je važna jer nastavnik kreira obrazovnu sredinu pri čemu treba da primenjuje raznovrsne obrazovne metode i tehnike. Babić -Kekez (2010) daje preporuke za modelovanje mentorskog rada kroz 6 etapa:

1. priprema rada sa učenikom,

2. stvaranje pozitivne sredine za učenje,

3. razvijanje plana učenja i poučavanja,

4. identifikacija ciljeva i aktivnosti učenja,

5. sprovođenje učenja i nadgledanje procesa,

6. evaluacija individualnih ishoda učenja.

Ovaj individualizovani pristup radu sa darovitima pruža benefite svim akterima. Sa jedne strane, darovitim učenicima omogućava veću autonomiju, emancipaciju, razvoj njihove autentičnosti i metakognitivnih sposobnosti dok nastavnik, kroz mentorski rad, može da izrazi svoje stvaralačke i kreativne potencijale. Dakle, ovakav podsticajni kontekst omogućava darovitim učenicima priliku za razvoj divergentnog mišljenja ali i metakognitivnih sposobnosti (Stojanović, 2016). Rezultati istraživanja sprovedenog u SAD od strane Lise Frenč i njenih saradnika (French, Walker \& Shore, 2011) koje se bavilo preferencijama darovitih učenika osnovne i srednje škole za samostalan rad ukazuju da daroviti nemaju podršku nastavnika u ovom obliku rada. Još jedno istraživanje, istraživanje autora Othausa (Olthouse 2012), čiju su populaciju činili učenici koji su daroviti u pisanju eseja, ukazuje da mladima nedostaje podrška za razvijanje njihovog talenta. Odgovori učenika ukazali su da im ne treba podrška koja će imati formu striktno i precizno definisanih zadataka, vec da se ostavi prostora za ispoljavanje njihove kreativnosti (Olthouse 2012). Upravo bi mentrorski rad mogao da bude odgovor na pitanje: kako podržati samostalan rad darovitih učenika? 


\section{Zaključna razmatranja}

Razvoj tehnike i tehnologije, postmoderna didaktička kultura ali i promene sadržaja učenja i uloga učesnika nastavnog procesa dovode do niza pitanja (i traganja) o efikasnosti učenja u nastavi sa posebnim akcentom na položaj ali i pedagoški tretman darovitih učenika. Daroviti pojedinac dragocen je resurs jedne nacije te njihov pravilan pedagoški tretman mora biti imperativ obrazovne politike. Stoga, neophodno je prevazići tradicionalne metode i oblike te se okrenuti organizaciji rada koja omogućava aktivniju ulogu učenika. Evidentno je da autentične potrebe darovitih učenika postavljaju drugačije zadatke pred nastavni proces ali i izazove pred same nastavnike jer u radu sa darovitim učenicima nastavnici moraju podjednako stimulisati intelektualnu ali i afektivnu komponentu ličnosti (Stipić i Lungulov, 2012). Dakle, pored razvoja viših intelektualnih sposobnosti, uloga nastavnika treba biti usmerena i na razvijanje svest o sebi kod darovitih te pozitivnog odnosa prema drugima. Primenom već navedenih, savremenih oblika i metoda nastavnog tada ostvaruje se veća individualizacija učenika, autonomija ali i emancipacija učenika, što su ujedno i opšte preporuke za rad sa darovitim učenicima (Mönks \& Katzko, 2005). Gledano kroz prizmu darovitih učeni$\mathrm{ka}$, donekle tradicionalan, mentorski rad, u reformskim promenama školskog sistema može da doživi „,novi procvat" i bude odličan ,alat" u rukama nastavnika. Mišljenja smo da je mentorska nastava izazov kako za učenike tako i za nastavnike zbog multidimenzionalnih uloga koje ovaj oblik rada iziskuje i prilika koje pruža nastavnicima za iskazivanje ličnog kreativnog potencijala. Ulogu mentora odlikuje sposobnost uvažavanja predloga učenika vezano za sadržaje koji će se obrađivati putem raznih projekata a rad ne treba organičiti samo na učionicu (zavisno od teme, sadržaje je moguće obrađivati i izvan škole u realnim životnim situacijama). Kada nastavnik preuzme ulogu mentora, on tada ostvaruje jedan od osnovnih principa vaspitanja, princip individualizacije. Na koncu, zaključujemo da je uloga nastavnika u radu sa darovitim učenicima kompleksna, multidimezionalna ali i delikatna te da se mora bazirati na podsticanju razvoja i učenja dece.

\section{Marina Mijatović}

\section{THE ROLE AND SIGNIFICANCE OF THE PRIMARY SCHOOL TEACHER IN THE EDUCATIONAL WORK WITH THE GIFTED}

Apstrakt:

In the scientific and professional community in the postmodern age, it is widely accepted that each individual should be enabled to achieve his/her predispositions and develop abilities to the individual's optimum. Therefore the focus is increasingly put 
on the question of the gifted learners. Giftedness is a personal but also social need because the gifted learners can grow into the social elite with adequate pedagogic treatment. Therefore, caring for gifted children is one of the important tasks of professional consultants, primary school teachers, secondary school teachers and preschool teachers. Primary school teachers have demanding and complex professional roles; their ability to use various methods and didactic-methodic procedures in order to meet the specific needs in the work with the gifted is very important. The aim of the paper is to indicate the complex role of the primary school teacher in the work with the gifted, as well as to give certain guidelines for organizing educational work with gifted learners.

Key words: giftedness, primary school teacher, educational work.

\section{Literatura}

Adžić, D. (2011). Darovitost i rad sa darovitim učenicima. Kako teoriju prenijeti u praksu. Život i škola25 (1), 171-184 .

Altaras, A. (2006). Darovitost i podbacivanje.Pančevo: Mali Nemo.

Babić-Kekez, S. (2010). Mentorski rad sa darovitim studentima. Preuzeto Mart 2019 sa: http://www.trend.uns.ac.rs/stskup/trend_2010/radovi/Tema2/T2.4-2. pdf.

Budimir-Ninković, G., Janković, A. (2016). Uloga nastavnika u podsticanju razvoja darovitih učenika. U: G. Gojkov, A. Stojanović (Ur.), Daroviti i didaktička kultura-Zbornik 21 (str 81-87). Vršac-Arad: Visoka škola strukovnih studija za vaspitače „Mihailo Palov“, Universitatea de Vest „Aurel Vlaicu“.

Branković, D., Mikanović, B. (2011). Emancipatorsko vaspitanje - osnov razvoja partnerskih odnosa u nastavi. Pedagoška stvarnost 7-8, 581-593.

Coleman, M. R. (2003). Four variables for success. Gifted Clild Today 26 (1), 22-24.

Čudina-Obradović, M. (1990). Nadarenost: razumijevanje, prepoznavanje i razvijanje, Zagreb: Školska knjiga.

Đorđević, B. (2005). Darovitost i kreativnost dece i mladih: Vršac: Visoka škola strukovnih studija za obrazovanje vaspitača „Mihailo Palov“.

Đorđević J., Đorđević, B. (2015). Didaktika darovitih. U: N. Potkonjak (U r.), Godišnjak Srpske akademije obrazovanja IX (str: 3 -122). Beograd: Srpska akademija obrazovanja.

Đukić, M., Đermanov, J., Kosanović, M. (2012). Pedagoški tretman darovitih učenika u inkluzivnoj školi. U: M. Đukić (Ur.), Inkluzivno obrazovanje: Obrazovanje za sve (str.61-90). Novi Sad: Filozofski fakultet, Univerzitet u Novom Sadu.

French, L. Walker, Ch \& Shore B. (2011). Do gifted Students Really Prefer to Work Alone? Roeper Rewiew33 (3), 145-159. 
Gallagher, S., Gallagher J. J. (2013). Using Problem-based learning to Explore Unseen Academic Potential. Interdisciplinary Journal of Problem-based Learning, 7 (1), 110-131.

George, D. (2004). Obrazovanje darovitih. Zagreb: Eduka.

Gojkov, G. (2008). Didaktika darovitih. Vršac: Visoka škola strukovnih studija za obrazovanje vaspitača „Mihailo Palov“.

Gojkov, G. (2016). Daroviti u didaktičkoj kulturi postmoderne.U: G. Gojkov, A. Stojanović (Ur.), Daroviti i didaktička kultura-Zbornik 21 (str 129-152). Vršac-Arad: Visoka škola strukovnih studija za vaspitače „Mihailo Palov“, Universitatea de Vest „Aurel Vlaicu“.

Grandić, R., Letić, M. (2009). Stanje, problemi i potrebe u području brige o darovitim učenicima u našem obrazovnom sistemu. U: G. Gojkov (Ur.), Daroviti $i$ društvena elita, Zbornik 15, (str. 232-243). Vršac: Visoka škola strukovnih studija za obrazovanje vaspitača „Mihailo Palov“, Universitatea „Aurel Vlaicu“ din Arad, Romania.

Koren, I. (1989). Kako prepoznati i identificirati nadarenog učenika. Zagreb: Školske novine.

Maksic, S. (1993). Kako prepoznati darovitog učenika. Beograd: Institut za pedagoška istraživanja.

Mönks, F. J. \& Katzko, M. W. (2005). Giftedness and gifted education. In: R. J. Sternberg \& J. E. Davidson (Eds.), Conceptions of giftedness( pp. 187-201). New York: Cambridge University Press.

Olthouse, J. (2012). Why I Write: What Tallented Creative Writers Need Their Teacher to Know. Gifted Child Today35 (2), 117-121.

Pavlović, J., Mijatović, M. (2016). Uspostavljanje i razvoj partnerskih odnosa u nastavi. U: G. Gojkov, A. Stojanović (Ur.), Daroviti i didaktička kultura-Zbornik 21 (str 274-281). Vršac-Arad: Visoka škola strukovnih studija za vaspitače ,Mihailo Palov“, Universitatea de Vest „Aurel Vlaicu“.

Policy and implementation strategiesfor the education of gifted and talented students (2004). New South Wales: Department of Education and Training.

Rotigel, J.V. (2003). Understanding the Young Gifted Child: Guidelines for Parents, Families and Educators. Early Childhood Education Journal 30 (4), 209-214.

Stipić, M., Lungulov, B. (2012). Obrazovanje darovitih u inkluzivnom kontekstu. U M. Đukić (Ur.), Inkluzivno obrazovanje: obrazovanje za sve (str. 91-107). Novi Sad: Filozofski fakultet, Univerzitet u Novom Sadu.

Stojanović, A. (2016). Položaj darovitih učenika u savremenoj didaktičkoj kulturi. U: G. Gojkov, A. Stojanović (Ur.), Daroviti i didaktička kultura-Zbornik 21 (str 307-317). Vršac-Arad: Visoka škola strukovnih studija za vaspitače „Mihailo Palov“, Universitatea de Vest „Aurel Vlaicu“.

Swanson, H. (1992). The relationship between metacognition and problem solving in gifted children. Roeper Rewiew 15 (1), 43-48. 
Tomić, O. (2012). Darovitost i etičnost. U: G. Gojkov; A. Stojanović (Ur.): Daroviti i moralnost, Zbornik 17 (str. 902-917). Vršac-Arad: Visoka škola strukovnih studija za obrazovanje vaspitača „Mihailo Palov”, Universitatea de Vest „Aurel Vlaicu".

Vaughn, C. R., Bos C. S, \& Schumm, J., S. (2009). Teaching students who are exeptional, diverse and at risk in general education classroom. Boston, MA: Pearsn Education Inc. Allyn and Bacon.

Winner, E. (2005). Darovita djeca, mitovi i stvarnost. Buševac: Ostvarenje. 